\title{
Telework in academia: associations with health and well-being among staff
}

\author{
Marina Heiden ${ }^{1}$ (D) $\cdot$ Linda Widar ${ }^{1} \cdot$ Birgitta Wiitavaara $^{1} \cdot$ Eva Boman $^{2}$
}

Published online: 24 July 2020

(C) The Author(s) 2020

\begin{abstract}
As the development of technical aids for telework has progressed, work has become more flexible in time and space. Among academics, the opportunity to telework has been embraced by most, but it is unclear how it relates to their health and well-being. The aim of this study was to determine how frequency and amount of telework is associated with perceived health, stress, recuperation, work-life balance, and intrinsic work motivation among teaching and research academics. An electronic questionnaire was sent to junior lecturers, senior lecturers, and professors at Swedish public universities. It included the General Health Questionnaire, Work Stress Questionnaire, items for assessing recuperation, the Basic Psychological Need Satisfaction at Work scale, and parts of Copenhagen Psychosocial Questionnaire, as well as questions about the frequency and amount of telework performed. In total, 392 academics responded to the survey. Multivariate analysis of variance showed significant differences between groups of academics with different telework frequency $(p<0.05)$. Univariate analyses of variance showed that ratings of stress related to indistinct organization and conflicts were higher among academics that telework several times per week or more than among academics that telework less than once per month. In regression analyses of associations between amount of telework (in hours per week) and the dependent variables, no significant effects were found. Although it cannot be concluded whether stress is a cause or an effect of frequent telework, the findings warrant further attention to academics who telework frequently.
\end{abstract}

Keywords Flexible work $\cdot$ Boundless work $\cdot$ Autonomy $\cdot$ Competence $\cdot$ Relatedness

\section{Introduction}

As the development of technical aids for telework has progressed, work has become more flexible in time and space (Allen et al. 2015; Vilhelmson and Thulin 2016). The opportunity to

Marina Heiden

marina.heiden@hig.se

Extended author information available on the last page of the article 
work away from the office at any time gives employees more autonomy in managing their work and balancing work with family demands, while it also puts higher demands on employees to set limits to their work (Currie and Eveline 2011). Arguably, limited boundary control in flexible working arrangements may contribute to excessive workload and overtime work, increased stress, and insufficient time for recovery (Mellner 2016). In a meta-analysis of studies on telework during regular working hours, however, Gajendran and Harrison (2007) found little evidence of telework being harmful to employees. Due to lack of information about job type and voluntariness of the telework arrangement in the studies, the potentially moderating effects of these factors were not studied. Others have argued that they are important for an employee's propensity to telework (cf. Scott et al. 2012).

The higher education system has undergone major changes in recent decades (Melin et al. 2014; Mudrak et al. 2018; Saltmarsh and Randell-Moon 2015). Technological development and increased competition nationally and internationally have led to gradually higher demands on efficiency and productivity, greater demand for distance learning, and expectations of staff being available anytime (Melin et al. 2014; Ng 2006; Saltmarsh 2011; Saltmarsh and RandellMoon 2015; Sutherland-Smith 2013). It has been argued that increased focus on management and performance evaluations have contributed to the deterioration of working conditions (Kenny 2018), and studies from several countries show that academics find their work situation demanding and report high levels of work-related stress (Bos et al. 2013; Kang and Sidhu 2015; Melin et al. 2014; Saltmarsh and Randell-Moon 2015). Among teaching and research staff, stressors have been identified as relationships with colleagues and superiors, high workload, lack of control over work, inadequate resources, work-life imbalance, and lack of personal development (Kang and Sidhu 2015; Ng 2006; Opstrup and Pihl-Thingvad 2016). Moreover, high work demands and lack of control over work were found to adversely affect staff health (Kang and Sidhu 2015; Makhbul and Khairuddin 2014). For this staff category, balancing teaching and research may prove especially difficult when productivity demands increase (Lai et al. 2014; Tight 2016). This may lead to longer working hours and poor worklife balance (Kinman and Jones 2008). In a recent study by Mudrak et al. (2018) on academic staff, the authors showed that job resources (e.g., influence over work and support from colleagues/supervisor) were related to work engagement and job satisfaction through a "motivational process," while job demands (e.g., job insecurity and work-family conflicts) were related to experienced stress through a "health-impairment process," within the framework of the job demands-resources model (Bakker 2011; Bakker and Demerouti 2014). Further, these processes appeared to be relatively independent, implying that academics are likely to remain engaged in their work despite increasing job demands, especially if sufficient job resources are provided. The authors argue that flexible working arrangements may benefit staff by leading to reduced stress.

Flexible working arrangements have increased gradually over time (Beatson 2019). Recent statistics from Eurofound (2017) show that approximately $44 \%$ of the working population in Europe can choose between different working schedules, adapt working hours within certain limits, or completely decide their working hours. According to Eurofound and the International Labour Office (2017), the incidence of telework or mobile work using information and communication technologies varies substantially across countries and is high in Finland, Japan, the Netherlands, Sweden, and the USA. In Sweden, about 40\% reported working from home at least once over the past 12 months, which is the second highest prevalence rate in Europe (OECD 2016). However, the opportunity for telework is unequally distributed across occupational groups. For example, it is more prevalent among "knowledge workers" (e.g., 
managers and professionals) (Eurofound and the International Labour Office 2017; OECD 2016).

To date, few studies have investigated how teaching and research staff in the higher education sector is affected by telework. In one study, it was found that staff with young children appreciated the possibility of managing a family alongside their work but reported that the benefits came at a cost of reduced leisure time, unless clear limits were set for work (Currie and Eveline 2011). The study also indicated gender differences in job satisfaction: men felt more satisfied with their work and the amount of work they performed, while women reported working too much and not being able to complete the tasks as planned. Tustin (2014) compared academic teleworkers and non-teleworkers and found that teleworkers felt more productive; more satisfied with their work; and estimated lower levels of stress, fatigue, and frustration than non-teleworkers. Similar results were obtained by Arvola and Kristjuhan (2015) when academic staff was asked about experienced stress during work outside the conventional office compared with work at the office. Although it was not possible to tell how the telework was distributed over time, their results also indicated that the extent of telework performed may be of importance for the staff's experience, as higher stress and more symptoms were indicated by those who did not telework as well as those who teleworked extensively. In a nationwide survey in the UK, Haddad et al. (2009) showed a higher prevalence of part-day homeworking than whole-day homeworking and that part-day homeworking was associated with avoiding interruptions at work, while whole-day homeworking was associated with commute struggle. The findings underline the importance of considering how telework is distributed over time when investigating its implications for employee health and well-being.

To get a better understanding of the relationship between telework, health, and well-being in academia, the aim of this study was to determine whether frequency or amount of telework is associated with perceived health, stress, recuperation, work-life balance, and intrinsic work motivation among teaching and research academics.

\section{Methods}

\section{Study design and participants}

The study was a cross-sectional survey of health, stress, recuperation, work-life balance, intrinsic work motivation, and extent of telework performed among teaching and research staff at Swedish public universities. Participants eligible for inclusion in the study were (i) employed as a junior lecturer, senior lecturer, or professor and (ii) engaged in teaching and/or research $\geq 50 \%$ of their working time.

\section{Data collection and processing}

Initially, an invitation to participate in the study was sent to the human resources departments of 24 Swedish universities. Of those who were invited, 6 universities agreed to distribute the online survey to their employees. These universities were located in urban and rural areas in the north, middle, and south of Sweden. Half of them were research focused. The survey was distributed through a link in an e-mail together with information about the study procedure and conditions for participation. Approximately 2 weeks after the survey was distributed, a 
reminder to answer it was sent out. The answers from the survey were collected through the SUNET Survey@ software (Artologik Survey \& Report). The data collection period lasted from May 2017 to March 2018, and the study was approved by the Regional Ethical Review Board in Uppsala, Sweden (Reg. no. 2016/494).

The survey contained 74 items, including the General Health Questionnaire (Hardy et al. 1999), the Work Stress Questionnaire (Holmgren et al. 2009), validated items for assessing recuperation (Gustafsson et al. 2006), the Basic Psychological Need Satisfaction at Work Scale (Deci and Ryan 2000; Eriksson and Boman 2018), and parts of Copenhagen Psychosocial Questionnaire (Berthelsen et al. 2014). In addition to these questionnaires, questions were included about the respondent's age, gender, family situation, form and extent of employment, work content, working time, and the extent of telework performed. A description of each instrument and the independent variables frequency and amount of telework is provided below.

\section{Dependent variables}

\section{Health}

Health was assessed by the 12-item version of the General Health Questionnaire (Hardy et al. 1999), where responses are given on 4-point scales ranging from "do not agree at all" to "completely agree." Some examples of items are "I can concentrate on what I do" and "I feel unhappy and depressed." After reversing 6 item scales, a total score was calculated using the Likert method (Hardy et al. 1999), thus ranging from 0 to 3 where higher values indicate better perceived health. The internal consistency of the instrument, in terms of Cronbach's alpha in the sample, was 0.84 .

\section{Work-related stress}

Work-related stress was assessed by the Work Stress Questionnaire (Holmgren et al. 2009). It consists of 21 items covering four categories of work characteristics: influence at work, indistinct organization and conflicts, individual demands and commitment, and work to leisure time interference. For influence at work (4 items, e.g. "Can you influence decisions at work?") and work to leisure time interference (3 items, e.g., "Does your work make it difficult to make time for your family?"), responses are given on 4-point scales ranging from "yes, always" to "no, never." A total score for each category was calculated as the median of responses in the category ranging from 1 to 4 where higher values indicate more influence and less interference, respectively (Holmgren 2008). For indistinct organization and conflicts ( 7 items, e.g., "Are the goals at your workplace clear?" and "Are there any conflicts at work?") and individual demands and commitment (7 items, e.g., "Do you often get engaged in your work?" and "Do you take too much responsibility at work?"), the respondent is asked to rate how stressful they perceive the item is on a 4-point scale ("not at all stressful" to "very stressful") and whether the item applies to the workplace. In case an item did not apply, the stress rating for that item was set to "not stressful." Then, a total score for each category was calculated as the median of stress ratings, ranging from 1 to 4 where higher values indicate less perceived stress. The internal consistency of the four scales, in terms of Cronbach's alpha in the sample, was 0.62 (influence at work), 0.82 (indistinct organization and conflicts), 0.88 (individual demands and commitment), and 0.90 (work to leisure time interference). 


\section{Recuperation}

Recuperation was assessed by 8 validated items covering fatigue (4 items, e.g., "Do you feel mentally tired after the working day?") and rest/recuperation (4 items, e.g., "Do you feel you have recovered and are thoroughly rested when you start work in the morning?") (Aronsson et al. 2003; Gustafsson et al. 2006). Responses are given on 5-point scales ranging from "never" to "very often", and one item scale for fatigue was reversed. For each category of items, a total score was then calculated as the mean of the responses in the category. The total scores ranged from 1 to 5, where higher values indicate less perceived fatigue and more rest/recuperation. The internal consistency of the scales, in terms of Cronbach's alpha in the sample, was 0.75 for fatigue and 0.91 for rest/recuperation.

\section{Work-life balance}

Work-life balance was assessed by the 4 items of work-family conflict in the work-individual interface domain of the Copenhagen Psychosocial Questionnaire (COPSOQ-II) (Berthelsen et al. 2014; Dicke et al. 2018). Some examples of items are "Do you often experience a conflict between your work and private life and that you would like to be in both places at the same time?" and "Do you feel that your work takes so much of your time that it has a negative effect on your private life?". Responses are given on 4-point scales ranging from "yes, certainly" to "no, not at all" and scored 0-100. Subsequently, a total score was calculated as the mean of the item scores (Berthelsen et al. 2014), where higher values indicate more work-life balance. The internal consistency of the scale, in terms of Cronbach's alpha in the sample, was 0.89 .

\section{Intrinsic work motivation}

Intrinsic work motivation was assessed by a Swedish version of the Basic Psychological Need Satisfaction at Work (BPNS-W) scale (Eriksson and Boman 2018), consisting of three dimensions: autonomy (7 items, e.g., "There is not much opportunity for me to decide for myself how to go about my work"), competence (6 items, e.g., "I do not feel very competent when I am at work"), and relatedness (8 items, e.g., "I get along with people at work"). Responses are given on 7-point scales ranging from "do not agree at all" to "completely agree." For each dimension, a total score was calculated as the mean of the item responses, after reversing 3 item scales per dimension. Thus, the total scores ranged from 1 to 7, where higher values indicate that the need for autonomy, competence, and relatedness is more satisfied, indicating a stronger intrinsic work motivation. The internal consistency of the scales, in terms of Cronbach's alpha in the sample, was 0.74 for autonomy, 0.59 for competence, and 0.82 for relatedness.

\section{Independent variables}

Among studies on telework, there is a lack of consistency in terminology and definition of the concept (Allen et al. 2015; De Croon et al. 2005). Given the context of this study, we have used the definition proposed by Allen et al. (2015), i.e., telework "is a work practice that involves members of an organization substituting a portion of their typical work hours (ranging from a few hours per week to nearly full-time) to work away from a central workplace- 
typically principally from home- using technology to interact with others as needed to conduct work tasks."

\section{Frequency of telework}

The frequency of telework was assessed with a single item: "How often do you work outside your conventional workplace?". Responses were given in one of the categories "never," "less than 1 time per month," "several times per month," "several times per week," or "always." Due to the small number of responses in the extreme categories (Table 1), the end categories "never" and "always" were merged with their adjacent category, generating the three categories "less than 1 time per month," "several times per month," and "several times per week or more."

\section{Amount of telework}

For a subset of the sample, an additional item was added to the survey about the average number of hours spent teleworking per week during the last month.

\section{Statistical analysis}

All analyses were performed in IBM SPSS Statistics 22.0 for Windows (IBM Corp., Armonk, NY, USA). Descriptive statistics of participants' characteristics are presented as proportions, means, and standard deviations. Multivariate and univariate analyses of variance were

Table 1 Characteristics of the respondents $(n=392)$

\begin{tabular}{|c|c|c|c|c|}
\hline & & Proportion & Mean & SD \\
\hline Age (years) & & & 48.9 & 9.9 \\
\hline \multirow[t]{2}{*}{ Gender } & Male & 37.2 & & \\
\hline & Female & 62.8 & & \\
\hline \multirow[t]{2}{*}{ Marital status } & Living alone & 14.6 & & \\
\hline & Living with partner & 79.1 & & \\
\hline Children at home & & 53.9 & & \\
\hline \multirow[t]{3}{*}{ Profession } & Junior lecturer & 45.0 & & \\
\hline & Senior lecturer & 44.2 & & \\
\hline & Professor & 10.8 & & \\
\hline \multirow[t]{2}{*}{ Form of employment } & Temporary & 12.2 & & \\
\hline & Permanent & 87.8 & & \\
\hline Extent of employment (\%) & & & 93.6 & 18.2 \\
\hline \multirow[t]{4}{*}{ Job content } & $\%$ teaching & & 62.9 & 88.7 \\
\hline & $\%$ research & & 23.7 & 26.0 \\
\hline & $\%$ management & & 8.0 & 17.2 \\
\hline & $\%$ other & & 11.8 & 15.1 \\
\hline Commuting time (min) & & & 72.2 & 127.8 \\
\hline \multirow{5}{*}{ Frequency of telework } & Never & 3.8 & & \\
\hline & Less than 1 time/month & 11.0 & & \\
\hline & Several times/month & 41.3 & & \\
\hline & Several times/week & 40.6 & & \\
\hline & Always & 3.3 & & \\
\hline Telework/week (h)* & & & 15.8 & 13.4 \\
\hline
\end{tabular}

$\mathrm{SD}$, standard deviation

*Number of respondents $=190$ 
performed with 11 scales of perceived health, work-related stress, recuperation, work-life balance, and intrinsic work motivation as dependent variables and frequency of telework as independent variable. The analyses were performed with and without adjustment for age, gender, marital status, children, form of employment, commuting time, and job content (i.e., proportion of research), as these variables were considered potentially important confounders (Bailey and Kurland 2002; Eurofound 2017; OECD 2016). Model assumptions in multivariate and univariate analysis of variance were checked using Box's M test, Levene's test, and standard graphical procedures.

For the subset of respondents that provided information about their amount of telework per week, regression models were fitted for each of the dependent variables with amount of telework as independent variable. The models were adjusted for age, gender, marital status, children, form of employment, commuting time, and proportion of research performed at work. In all tests, $p<0.05$ was considered significant.

\section{Results}

In total, 392 academics responded to the survey, yielding a response rate of $14 \%$ (7-21\% across the universities). Respondent characteristics are shown in Table 1. The proportion of junior lecturers in the sample was similar to that in the population (45\% in the sample and $44 \%$ in the population), while the proportion of senior lecturers was slightly larger (44\% in the sample and $42 \%$ in the population), and the proportion of professors was smaller (11\% in the sample and $14 \%$ in the population). The sample contained a higher proportion of women than the population (62\% in the sample and $52 \%$ in the population).

On average, the participants rated relatively good health (2.2 of $3=$ perfect health), autonomy ( 4.9 of $7=$ maximum satisfaction), competence ( 5.4 of $7=$ maximum satisfaction), and relatedness ( 5.3 of $7=$ maximum satisfaction). They experienced a small amount of stress related to influence at work ( 2.8 of $4=$ no stress), indistinct organization and conflicts ( 3.5 of 4 $=$ no stress), individual demands and commitment ( 2.6 of $4=$ no stress), and work to leisure time interference ( 2.6 of $4=$ no stress). They felt quite often rested/recuperated ( 3.8 of $5=$ fully rested/recuperated) and sometimes fatigued during and after work ( 3.2 of $5=$ never fatigued). Their ratings of work-life balance averaged 53 of 100, where 100 indicated perfect balance.

\section{Frequency of telework}

The multivariate analysis of variance showed significant differences between groups of academics with different telework frequency $(p=0.005$, Table 2$)$. When the analysis was adjusted for age, gender, marital status, children at home, form of employment, commuting time, and proportion of research performed at work, the results did not change (Table 2). However, age, gender, marital status, and form of employment were significant.

Separate analyses of variance for each of the 11 dependent variables showed significant differences in fatigue $(F=3.47 ; p=0.032)$ and stress related to indistinct organization and conflicts $(F=4.80 ; p=0.009)$ between academics with different telework frequency (Table 3$)$. Bonferroni's pairwise post hoc tests between telework categories showed that those who telework frequently (i.e., several times per week or more) reported more stress related to indistinct organization and conflicts than those who rarely telework (i.e., less than 1 time per month) (mean and standard deviation $3.33 \pm 0.87$ versus $3.72 \pm 0.63 ; p=0.006$ ). For fatigue, 
Table 2 Results from multivariate analysis of variance with and without adjustment for age, gender, marital status, children at home, form of employment, commuting time, and proportion of research performed at work

\begin{tabular}{lrllcr}
\hline & Wilks' $\lambda$ & $F$ & $p$ & Partial $\eta^{2}$ & Power \\
\hline Tcom & $\mathbf{0 . 8 9}$ & $\mathbf{1 . 9 9}$ & $\mathbf{0 . 0 0 5}$ & $\mathbf{0 . 0 6}$ & $\mathbf{0 . 9 9}$ \\
Tcom & & & & & $\mathbf{0 . 0 6}$ \\
Age & $\mathbf{0 . 8 8}$ & $\mathbf{2 . 1 8}$ & $\mathbf{0 . 0 0 1}$ & $\mathbf{0 . 9 9}$ \\
Gender & $\mathbf{0 . 9 5}$ & $\mathbf{1 . 9 1}$ & $\mathbf{0 . 0 3 7}$ & $\mathbf{0 . 0 5}$ & $\mathbf{0 . 8 9}$ \\
Marital status & $\mathbf{0 . 9 3}$ & $\mathbf{2 . 6 9}$ & $\mathbf{0 . 0 0 2}$ & $\mathbf{0 . 0 7}$ & $\mathbf{0 . 9 8}$ \\
Children & $\mathbf{0 . 9 4}$ & $\mathbf{2 . 1 9}$ & $\mathbf{0 . 0 1 5}$ & $\mathbf{0 . 0 6}$ & $\mathbf{0 . 9 3}$ \\
EmployForm & 0.97 & 1.16 & 0.312 & 0.03 & 0.64 \\
ComTime & $\mathbf{0 . 9 4}$ & $\mathbf{2 . 1 2}$ & $\mathbf{0 . 0 1 8}$ & $\mathbf{0 . 0 6}$ & $\mathbf{0 . 9 2}$ \\
Research & 0.98 & 0.75 & 0.695 & 0.02 & 0.42 \\
\hline
\end{tabular}

Significant differences are shown in bold. Tcom, frequency of telework (less than 1 time per month/several times per month/several times per week or more); children, children at home (yes/no); EmployForm, form of employment (temporary/permanent position); ComTime, commuting time (minutes); research, proportion of research performed at work (\%). Dependent variables: 11 scales of perceived health, work-related stress, recuperation, work-life balance and intrinsic work motivation (listwise $n=369$ )

the pairwise difference did not reach significance (mean and standard deviation $3.11 \pm 0.75$ versus $3.35 \pm 0.72 ; p=0.069$ ).

After adjusting for age, gender, marital status, children at home, form of employment, commuting time, and proportion of research performed at work, the results did not change for frequency of telework (Table 3). Age was positively associated with ratings of autonomy, stress related to individual demands and commitment, and fatigue. Gender differences were found in ratings of relatedness, stress related to indistinct organization and conflicts, stress related to individual demands and commitment, and fatigue. While women reported more stress and fatigue than men did, they reported a more satisfied need for relatedness at work. Marital status, i.e., living with partner, significantly contributed to higher ratings of health, autonomy, relatedness, rest/recuperation, and less stress related to indistinct organization and conflicts. Those who had a temporary position reported less satisfied need for competence and relatedness at work and less stress related to indistinct organization and conflicts, compared with those who had a permanent position. Although children at home and proportion of research performed at work were not significant in the multivariate analysis of variance, we found that having children at home was associated with less satisfied need for competence at work and more stress related to indistinct organization and conflicts, and performing more research at work was associated with less work-life balance.

In the multivariate analysis of variance, Box's M test was nonsignificant ( $p=0.267)$, and equal variance across groups could be assumed for all dependent variables except stress related to indistinct organization and conflicts (Levene's test, $p<0.001$ ). In the adjusted analysis, Box's $M$ test was significant $(p=0.017)$, and equal variance across groups could not be assumed for stress related to indistinct organization and conflicts, individual demands and commitment, and work to leisure time interference, as well as ratings of relatedness, rest/recuperation, and fatigue. The majority of the residuals were not normally distributed.

\section{Amount of telework}

In linear regression analyses of associations between amount of telework (in hours per week) and the dependent variables, no significant effects were found (Table 4). Among the 


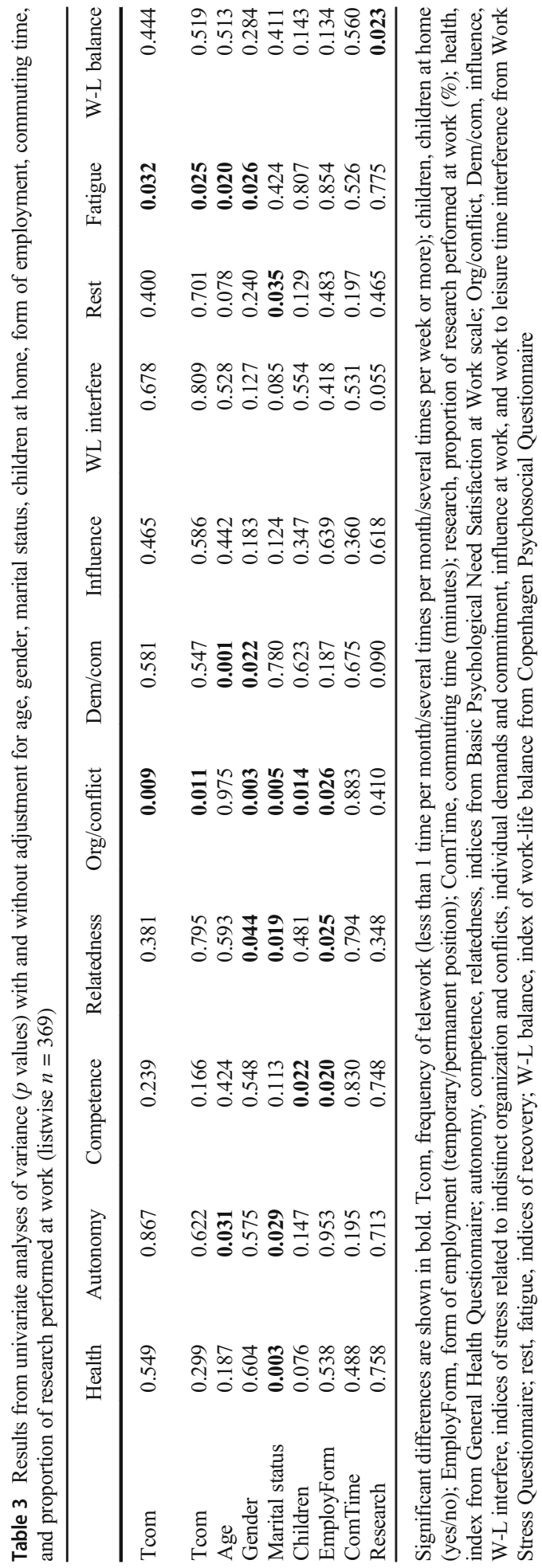




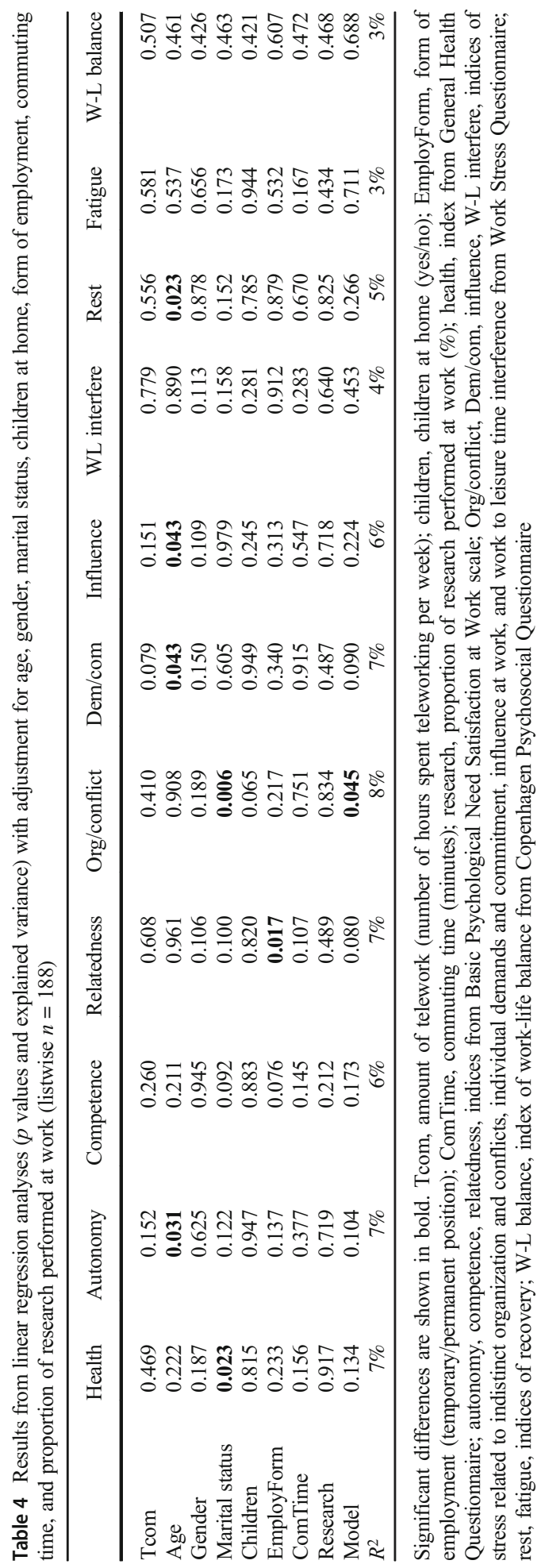


predictors, age was associated with higher ratings of autonomy, influence at work and rest/recuperation, and less stress related to individual demands and commitment. Marital status, i.e., living with partner, was associated with better perceived health and less stress related to indistinct organization and conflicts. Those who had a temporary position reported less satisfied need for relatedness at work compared with those who had a permanent position. Values of tolerance and variance inflation factor indicated no problems with collinearity in the models (tolerance, 0.65-0.94; variance inflation factor, 1.06-1.54).

In the ratings of amount of telework, 3 respondents answered $>40 \mathrm{~h}$ per week, indicating a substantial amount of overtime work. To determine the effect of these outliers, the regression analyses were rerun without them, and the results remained the same. Further, the addition of non-linear effects of amount of telework did not change the results.

\section{Discussion}

In the present study, we compared perceived health, stress, recuperation, work-life balance, and intrinsic work motivation between lecturers and professors with different telework frequency. We found higher ratings of stress related to indistinct organization and conflicts among academics that telework several times per week or more than among academics that telework less than once per month, albeit with rather small effect size. When amount of telework in terms of hours per week was associated to health, stress, recuperation, work-life balance, and intrinsic work motivation, on the other hand, no significant effects were found.

Our finding that high frequency of telework was associated with higher ratings of stress stand in contrast to a previous study reporting lower levels of stress among teleworking academics (Tustin 2014). Further, we did not find a curvilinear relationship between reported symptoms and amount of telework, as indicated by Arvola and Kristjuhan (2015) when comparing categories of telework usage in hours per week. The difference in findings may reflect cultural differences between South Africa, Estonia, and Sweden. The findings may also be related to the context in which the study was performed and how the samples were selected. While Tustin (2014) reported on an experimental telecommuting program at a large distance education institution, Arvola and Kristjuhan (2015) studied telework in one university where employees were used to work from home. In the present study, data were collected from 6 urban and rural universities across Sweden, where employees have had the option to telework for decades. Almost $90 \%$ of the respondents had a permanent position, and they reported more stress than those who had a temporary position. It is possible that the main reason for teleworking in our sample was to cope with increasing job demands (Tremblay et al. 2006) and that higher frequency of telework implied working longer hours. This could not be verified in the present study but might partly explain the tendency for high frequent teleworkers to rate more fatigue.

It has been argued that telework facilitates the balancing of competing work and family demands (Fonner and Roloff 2010; Percival et al. 2011). That does not appear to be the case among academics. We found no difference in ratings of work-life balance between lecturers and professors with different telework frequency or any association between the amount of telework performed per week and perceived work-life balance. Golden et al. (2006) showed that as the extent of telework increases, individuals experience less work-to-family conflict but more family-to-work conflict. Thus, they may cancel each other out, leading to no effect on overall work-life balance. In this study, most of the items included in the scales focused on work-to-family conflict rather than family-to-work conflict. Yet, we found no support for 
work-to-family conflict being related to the extent of telework in this population. The findings are in agreement with a recent study on employees in Swedish government agencies (including one university), where Thulin et al. (2019) showed that perceived control over daily time use was not related to teleworking practice or type of work (i.e., predominantly routine case control tasks or predominantly autonomous and investigative tasks).

According to self-determination theory, three basic needs are required to be motivated at work (Deci and Ryan 2000). These are autonomy (i.e., the degree of freedom and choice experienced when performing one's job), competence (i.e., the participation in challenging tasks and experience of effectiveness at work), and relatedness (i.e., the feeling of caring for, and being cared of, by colleagues). Interestingly, none of these were associated with the frequency or amount of telework among academics. This suggests that academics are equally satisfied with their autonomy at work, community with colleagues, and they feel equally efficient at work, regardless of how much they telework. Our result does not support previous findings of increased perceived productivity among teleworking academics (Tustin 2014). Possibly, the lack of agreement between the studies is due to the categorization of personnel: in Tustin (2014), teleworking academics consisted of professors and associate professors that had officially been granted permission to work part-time from home, while those that did not telework were office-bound. In our sample, lecturers and professors all had the opportunity to telework and chose to do so to different extents. It may be that, as the option to telework is available to everyone, it loses its appeal and that is reflected in the staff's ratings. Naturally, these self-ratings of effectiveness at work may differ from productivity ratings from other parties, such as management or colleagues (Golden and Gajendran 2018; Percival et al. 2011). In any case, our findings bring into question the use of telework to improve work motivation among academics.

We found no difference in ratings of relatedness to other colleagues between lecturers and professors that telework to different extents. This may lend support to previous findings that telework has limited impact on communication within the organization and that high-frequent teleworkers are not being left out of the network (Belanger 1999; Duxbury and Neufeld 1999). From this study, however, the impact of telework can only be understood from the perspective of the individual who teleworks. It is possible that lower levels of stress due to meetings and interruptions that have been reported among teleworkers (Fonner and Roloff 2010) are achieved at the expense of others having to do more service work (Bailey and Kurland 2002; Percival et al. 2011), and this could lead to conflicts between colleagues. Indeed, we found higher ratings of stress related to indistinct organization and conflicts among academics that telework frequently.

Among the factors adjusted for in the analyses of variance, the only one that did not significantly contribute to any of the dependent variables was commuting time. Previous literature disagrees on the importance of commuting time/distance for telework frequency (Bailey and Kurland 2002; Helminen and Ristimaki 2007; Hjorthol 2006; Melo and Silva 2017). A recent study on academic staff showed that delay time during travel, but not travel time itself, was an important determinant for the preference towards telework (Ismail et al. 2018). Then again, factors determining the preference towards telework may be different from factors associated with actual telework frequency (Haddad et al. 2009; Percival et al. 2011).

In this study, extent of telework was assessed in terms of both frequency and amount. The results differed depending on which variable was analyzed. While differences were found in stress related to indistinct organization and conflicts between high- and low-frequent teleworkers, no association between amount of telework and any of the measures of health, 
stress, recuperation, work-life balance, and intrinsic work motivation was found. It would appear that, among academics, the frequency of telework is more important for these outcomes than the amount of telework. Admittedly, the number of respondents included in the analyses of telework amount was much smaller than the number of respondents in the analyses of telework frequency, and this could have affected the results.

\section{Limitations}

Due to the cross-sectional design of the present study, we cannot determine whether increased stress related to indistinct organization and conflicts is a cause or an effect of frequent telework. Both explanations are plausible, since experience of stress at work can trigger an escape mechanism that is manifested through frequent telework. High frequent telework among some of the staff may, in turn, burden colleagues that do not engage in this work mode, causing friction among colleagues (Bailey and Kurland 2002; Golden 2007).

Another limitation of the study was the low response frequency, which may bias the results. The response rate was higher in the universities that were more teaching focused (15-21\%) than the universities that were more research focused (7-11\%). Thus, it is possible that the findings of higher stress ratings among high-frequency teleworkers apply more to lecturers in teaching focused universities. In light of the gender differences observed in the ratings and the fact that the sample contained a larger proportion of women than the population, the generalization of the findings may be limited. Further, the internal consistency of the competence scale of BPNS-W and the influence at work scale of the Work Stress Questionnaire was low. In this study, we assessed the current frequency and amount of telework among academics, but we did not investigate whether it varied over time or how long they had practiced telework. It is suggested that this be included in future studies, as it may affect the results.

\section{Conclusions}

The present study showed that frequent telework was associated with increased stress among academics that all had the opportunity to telework. We found no evidence of intrinsic work motivation, work-life balance, or general health being related to frequency of telework. Nor did we find that amount of telework had any association with the outcomes. The different findings for frequency and amount of telework support previous studies emphasizing the importance of considering how telework is distributed over time (cf. Haddad et al. 2009) and should be verified in larger samples as they may have implications for recommendations regarding telework practice.

Considering the situation in academia, particularly with respect to work-life balance among employees, flexible working arrangements have been proposed as a means to reduce stress (Mudrak et al. 2018). In light of the present findings, we argue that teleworking may not ease the situation. Although we cannot conclude whether stress is a cause or an effect of frequent telework, the results show that academics who telework several times per week or more experience more stress related to indistinct organization and conflicts than others. Thus, more attention to academics who telework frequently is warranted.

Acknowledgments We would like to thank all study participants and the human resources departments of the universities who assisted us in the data collection. 
Funding information Open access funding provided by University of Gävle. This study was funded by the University of Gävle, Sweden.

\section{Compliance with ethical standards}

Conflicts of interest The authors declare no conflict of interest with regard to the source of funding for the research or any other support that would have biased the research.

Open Access This article is licensed under a Creative Commons Attribution 4.0 International License, which permits use, sharing, adaptation, distribution and reproduction in any medium or format, as long as you give appropriate credit to the original author(s) and the source, provide a link to the Creative Commons licence, and indicate if changes were made. The images or other third party material in this article are included in the article's Creative Commons licence, unless indicated otherwise in a credit line to the material. If material is not included in the article's Creative Commons licence and your intended use is not permitted by statutory regulation or exceeds the permitted use, you will need to obtain permission directly from the copyright holder. To view a copy of this licence, visit http://creativecommons.org/licenses/by/4.0/.

\section{References}

Allen, T. D., Golden, T. D., \& Shockley, K. M. (2015). How effective is telecommuting? Assessing the status of our scientific findings. Psychological Science in the Public Interest, 16(2), 40-68.

Aronsson, G., Svensson, L., \& Gustafsson, K. (2003). Unwinding, recuperation, and health among compulsory school and high school teachers in Sweden. International Journal of Stress Management, 10(3), 217-234.

Arvola, R., \& Kristjuhan, U. (2015). Workload and health of older academic personnel using telework. Agronomy Research, 13(3), 741-749.

Bailey, D. E., \& Kurland, N. B. (2002). A review of telework research: Findings, new directions, and lessons for the study of modern work. Journal of Organizational Behavior, 23, 383-400.

Bakker, A. B. (2011). An evidence-based model of work engagement. Current Directions in Psychological Science, 20(4), 265-269.

Bakker, A. B., \& Demerouti, E. (2014). Job demands-resources theory. In C. C. P. Chen (Ed.), Wellbeing. A Complete reference guide (pp. 37-64). Chichester: Wiley-Blackwell.

Beatson, M. (2019). Megatrends - Flexible working. London: Chartered Institute of Personnel and Development.

Belanger, F. (1999). Communication patterns in distributed work groups: A network analysis. IEEE Transactions on Professional Communication, 42(4), 261-275.

Berthelsen, H., Westerlund, H., \& Sondergård Kristensen, T. (2014). COPSOQ II - en uppdatering och språklig validering av den svenska versionen av en enkät för kartläggning av den psykosociala arbetsmiljön på arbetsplatser. Stockholm: Stress Research Institute, Stockholm University.

Bos, J. T., Donders, N. C., van der Velden, K., \& van der Gulden, J. W. (2013). Perceptions of mental workload in Dutch university employees of different ages: A focus group study. BMC Research Notes, 6, 102.

Currie, J., \& Eveline, J. (2011). E-technology and work/life balance for academics with young children. Higher Education, 62, 533-550.

De Croon, E. M., Sluiter, J. K., Kuijer, P. P. F. M., \& Frings-Dresen, M. H. W. (2005). The effect of office concepts on worker health and performance: A systematic review of the literature. Ergonomics, 48(2), 119134.

Deci, E. L., \& Ryan, R. M. (2000). The "what" and "why" of goal pursuits: Human needs and the selfdetermination of behavior. Psychological Inquiry, 11(4), 227-268.

Dicke, T., Marsh, H. W., Riley, P., Parker, P. D., Guo, J. S., \& Horwood, M. (2018). Validating the Copenhagen psychosocial questionnaire (COPSOQ-II) using set-ESEM: Identifying psychosocial risk factors in a sample of school principals. Frontiers in Psychology, 9, 584.

Duxbury, L., \& Neufeld, D. (1999). An empirical evaluation of the impacts of telecommuting on intraorganizational communication. Journal of Engineering and Technology Management, 16(1), 1-28.

Eriksson, M., \& Boman, E. (2018). Short is beautiful: Dimensionality and measurement invariance in two length of the basic psychological need satisfaction at work scale. Frontiers in Psychology, 9, 965.

Eurofound. (2017). European Quality of Life Survey 2016. Luxembourg: Publications Office of the European Union.

Eurofound and the International Labour Office. (2017). Working anytime, anywhere: The effects on the world of work. Luxembourg: Publications Office of the European Union and the International Labour Office. 
Fonner, K. L., \& Roloff, M. E. (2010). Why teleworkers are more satisfied with their jobs than are office-based workers: When less contact is beneficial. Journal of Applied Communication Research, 38(4), 336-361.

Gajendran, R. S., \& Harrison, D. A. (2007). The good, the bad, and the unknown about telecommuting: metaanalysis of psychological mediators and individual consequences. Journal of Applied Psychology, 92(6), $1524-1541$.

Golden, T. (2007). Co-workers who telework and the impact on those in the office: Understanding the implications of virtual work for co-worker satisfaction and turnover intentions. Human Relations; Studies Towards the Integration of the Social Sciences, 60(11), 1641-1667.

Golden, T. D., \& Gajendran, R. S. (2018). Unpacking the role of a telecommuter's job in their performance: Examining job complexity, problem solving, interdependence, and social support. Journal of Business and Psychology. https://doi.org/10.1007/s10869-018-9530-4.

Golden, T. D., Veiga, J. F., \& Simsek, Z. (2006). Telecommuting's differential impact on work-family conflict: Is there no place like home? The Journal of Applied Psychology, 91(6), 1340-1350.

Gustafsson, K., Lindfors, P., Aronsson, A., \& Lundberg, U. (2006). Validering av frågor avseende nedvarvning och återhämtning - samband mellan salivkortisol och subjektiva skattningar. Stockholm: National Institute for Working Life.

Haddad, H., Lyons, G., \& Chatterjee, K. (2009). An examination of determinants influencing the desire for and frequency of part-day and whole-day homeworking. Journal of Transport Geography, 17(2), 124-133.

Hardy, G. E., Shapiro, D. A., Haynes, C. E., \& Rick, J. E. (1999). Validation of the general health questionnaire12 using a sample of employees from England's health care services. Psychological Assessment, 11(2), 159165.

Helminen, V., \& Ristimaki, M. (2007). Relationships between commuting distance, frequency and telework in Finland. Journal of Transport Geography, 15(5), 331-342.

Hjorthol, R. J. (2006). Teleworking in some Norwegian urban areas - Motives and transport effects. Urban Geography, 27(7), 610-627.

Holmgren, K. (2008). Work-related stress in women: Assessment, prevalence and return to work, Dissertation, University of Gothenburg, ISBN 978-91-628-7537-4, Gothenburg.

Holmgren, K., Hensing, G., \& Dahlin-Ivanoff, S. (2009). Development of a questionnaire assessing work-related stress in women-identifying individuals who risk being put on sick leave. Disability and Rehabilitation, 31(4), 284-292.

Ismail, F. D., Hamsa, A. A. K., \& Mohamed, M. Z. (2018). Modelling the effects of factors on the stated preference towards telecommuting in IIUM campus, Gombak. International Journal of Urban Sciences. https://doi.org/10.1080/12265934.2018.1446352.

Kang, L. S., \& Sidhu, H. (2015). Identification of stressors at work: A study of university teachers in India. Global Business Review, 16(2), 303-320.

Kenny, J. (2018). Re-empowering academics in a corporate culture: An exploration of workload and performativity in a university. Higher Education, 75, 365-380.

Kinman, G., \& Jones, F. (2008). A life beyond work? Job demands, work-life balance, and wellbeing in UK academics. Journal of Human Behavior in the Social Environment, 17(1-2), 41-60.

Lai, M., Du, P., \& Linlin, L. (2014). Struggling to handle teaching and research: A study on academic work at select universities in the Chinese Mainland. Teaching in Higher Education, 19(8), 966-979.

Makhbul, Z. M., \& Khairuddin, S. M. H. H. S. (2014). The effect of occupational stressors on health and individual productivity: Assessments via Sobel test. JEM, 48(1), 117-131.

Melin, M., Astvik, W., \& Bernhard-Oettel, C. (2014). New work demands in higher education. A study of the relationship between excessive workload, coping strategies and subsequent health among academic staff. Quality in Higher Education, 20(3), 290-308.

Mellner, C. (2016). After-hours availability expectations, work-related smartphone use during leisure, and psychological detachment: The moderating role of boundary control. International Journal of Workplace Health Management, 9(2), 146-164.

Melo, P. C., \& Silva, J. D. E. (2017). Home telework and household commuting patterns in Great Britain. Transportation Research Part A: Policy and Practice, 103, 1-24.

Mudrak, J., Zabrodska, K., Kveton, P., Jelinek, M., Blatny, M., Solcova, I., \& Machovcova, K. (2018). Occupational well-being among university faculty: A job demands-resources model. Research in Higher Education, 59, 325-348.

$\mathrm{Ng}, \mathrm{C}$. F. (2006). Academics telecommuting in open and distance education universities: Issues, challenges, and opportunities. International Review of Research in Open and Distance Learning, 7(2).

OECD. (2016). Be flexible! Background brief on how workplace flexibility can help European employees to balance work and family. Paris: OECD Publishing.

Opstrup, N., \& Pihl-Thingvad, S. (2016). Stressing academia? Stress-as-offence-to-self at Danish universities. Journal of Higher Education Policy and Management, 38(1), 39-52. 
Percival, J., Vogel, E., \& Muirhead, B. (2011). Telecommuting in higher education: Faculty perceptions of strategic implications for traditional postsecondary institutions. International Journal of Management Education, 5(2/3), 271-284.

Saltmarsh, S. (2011). Economic subjectivities in higher education - Self, policy and practice in the knowledge economy. Cultural Studies Review, 17(2), 115-139.

Saltmarsh, S., \& Randell-Moon, H. (2015). Managing the risky humanity of academic workers: Risk and reciprocity in university work-life balance policies. Policy Futures in Education, 13(5), 662-682.

Scott, D. M., Dam, I., Paez, A., \& Wilton, R. D. (2012). Investigating the effects of social influence on the choice to telework. Environment \& Planning A, 44(5), 1016-1031.

Sutherland-Smith, W. (2013). Competition or collaboration: policies and practices in international higher education. Australian Educational Researcher, 40(3), 391-401.

Thulin, E., Vilhelmson, B., \& Johansson, M. (2019). New telework, time pressure, and time use control in everyday life. Sustainability, 11, 3067.

Tight, M. (2016). Examining the research/teaching nexus. European Journal of Higher Education, 6(4), 293311.

Tremblay, T.-G., Paquet, R., \& Najem, E. (2006). Telework: A way to balance work and family or an increase in work-family conflict? Canadian Journal of Communication, 31(3). https://doi.org/10.22230/cjc.2006v31n3 a1721.

Tustin, D. H. (2014). Telecommuting academics within an open distance education environment of South Africa: More content, productive, and healthy? International Review of Research in Open and Distance Learning, 15(3), 185-214.

Vilhelmson, B., \& Thulin, E. (2016). Who and where are the flexible workers? Exploring the current diffusion of telework in Sweden. New Technology, Work and Employment, 31(1), 77-96.

Publisher's note Springer Nature remains neutral with regard to jurisdictional claims in published maps and institutional affiliations.

\section{Affiliations}

\section{Marina Heiden $^{1} \cdot$ Linda Widar $^{1} \cdot$ Birgitta Wiitavaara $^{1} \cdot$ Eva Boman $^{2}$}

Linda Widar

linda.widar@hig.se

Birgitta Wiitavaara

birgitta.wiitavaara@hig.se

Eva Boman

eva.boman@hig.se

1 Centre for Musculoskeletal Research, Department of Occupational Health Science and Psychology, Faculty of Health and Occupational Studies, University of Gävle, SE-801 76 Gävle, Sweden

2 Department of Occupational Health Science and Psychology, Faculty of Health and Occupational Studies, University of Gävle, SE-801 76 Gävle, Sweden 